\title{
Desain dan Pembuatan Cetakan Sistem Injeksi untuk Cetakan Plastik Adonan Donat
}

\author{
Syamsul Hadi ${ }^{1, a}$, Tandya Nanda Haswari Murti ${ }^{2, b}$, Saifudin Kalih Sayekti ${ }^{3, c}$, dan Agus Setiawan ${ }^{4, d}$ \\ 1,2,3,4 Jurusan Teknik Mesin, Politeknik Negeri Malang, Jl. Soekarno-Hatta 9 Malang 65141, Indonesia \\ a syampo12003@yahoo.com ,b diio.nanda@gmail.com, , saifudinks@yahoo.co.id, ${ }^{\mathrm{d}}$ agus.setiawan@polinema.ac.id
}

\begin{abstract}
The problem lies in the length of process, it is hard to make, and a donut shape (circle-shaped cake and hollow in the middle) are not good made by the domestic industry that created manually (by hand). The purpose of the design and manufacture of plastic mold injection molding system for donuts is to speed up the processing of dough donut with easy and efficient way. Methods of design and manufacture of plastic molding dough donut capacity of 30 product/hour with injection system include: survey for dimensions of donuts on the market, determining the thermal expansion of the dough after frying for the determination of shrinkage in the dimensions of the mold, mold design on the top and bottom, the design of cooling systems, the design for ejection system for mold products, working drawings, machining components, assembly, testing, and the calculation of production costs. The results of the design and manufacture of plastic molding dough donut is a donut molds for parts of the top and bottom made of plastic material types of polypropylene (PP).
\end{abstract}

Keywords--design, plastic molding, injection system, mold dough donut, and polypropylene (PP).

Abstrak--Masalah terletak pada lamanya proses, sulit pembuatannya, dan bentuk donat (kue berbentuk lingkaran dan berlubang di tengahnya) yang tidak bagus yang dibuat oleh industri rumah tangga secara manual (dengan tangan). Tujuan dari desain dan pembuatan cetakan plastik sistem injeksi cetakan untuk donat adalah untuk mempercepat proses pengolahan adonan donat dengan cara mudah dan efisien. Metode desain dan pembuatan cetak plastik adonan donat kapasitas 30 produk/jam dengan sistem injeksi meliputi: survey dimensi donat di pasaran, penentuan pemuaian adonan setelah digoreng untuk penentuan penyusutan/shrinkage pada dimensi cetakan, desain cetakan pada bagian atas dan bawah, desain sistem pendinginan, desain sistem untuk pendepakan/ejection produk cetakan, pembuatan gambar kerja, pemesinan komponen-komponen, perakitan, uji coba, dan perhitungan biaya produksi. Hasil desain dan pembuatan cetak plastik adonan donat adalah sepasang cetakan donat untuk bagian-bagian atas dan bawah yang dibuat dari bahan plastik jenis polypropylene (PP).

Kata-kunci-kata kunc--desain cetakan, cetakan plastik, sistem injeksi, dan cetakan adonan donat, dan polypropylene.

\section{Pendahuluan}

Perkembangan pembuatan cetakan diawali dengan pembuatan cetakan sederhana yang terbuat dari pelat stainless steel yang banyak beredar di pasaran sebagaimana Gambar 1 [1]. Setelah adonan donat cukup kenyal ditaruh dalam suatu landasan dengan ketebalan tertentu, lalu adonan ditekan sambil cetakan diputar untuk mengirisnya menjadi suatu bentuk cincin yang lebihan adonannya dipisahkan. Adonan berupa cincin siap digoreng.

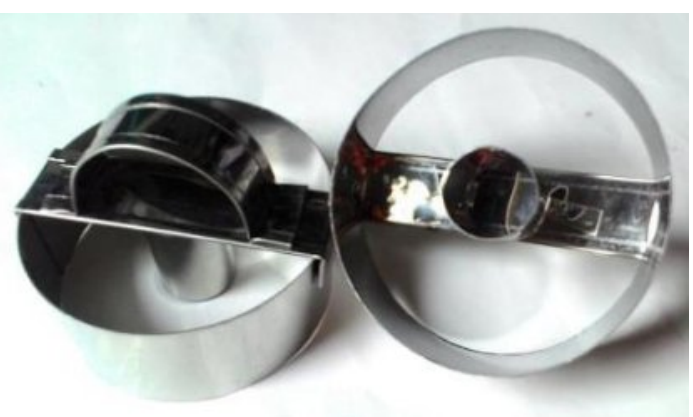

Gambar 1. Cetakan donat sederhana terbuat dari pelat stainless steel [1]

Perkembangan cetakan donat selanjutnya berupa Irus Cetakan Donat Cair yaitu adonan donat cair diambil dengan sebuah irus dan langsung dimasukkan ke dalam minyak goreng panas, setelah cukup mengeras, lalu Irus diambil sebagaimana Gambar 2 [2]. Bentuk donat yang dihasilkan berupa cincin yang bagian atasnya cenderung mendatar. 


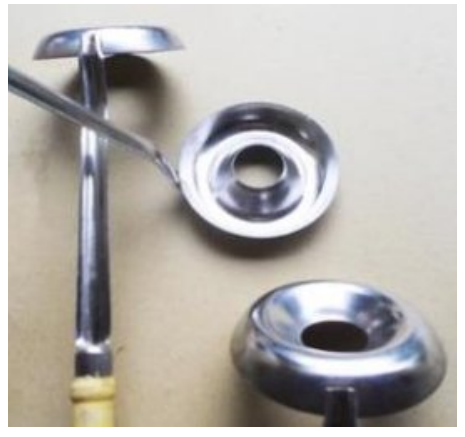

Gambar 2. Irus Cetakan Donat Cair [2]

Lebih jauh telah dibuat wajan pencetak donat oleh suatu perusahaan yang memerlukan teknologi dan modal yang tinggi sebagaimana Gambar 3 [3]. Bentuk yang dihasilkan mengikuti volume cetakan yang tersedia, jumlah dan besarnya pemuaian adonan menjadi faktor penentu bentuk akhir donat yang dibuat dengan wajan pencetak.

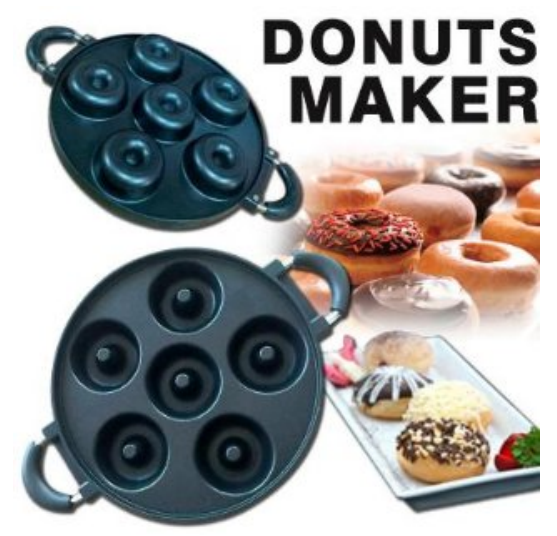

Gambar 3. Wajan pencetak donat buatan suatu perusahaan berteknologi dan modal tinggi [3]

Di sisi lain, bentuk dan cara sederhana adonan donat yang cukup kenyal dicetak dengan mangkok pencetak adonan donat dari Aluminium sebagaimana Gambar 4 [4].

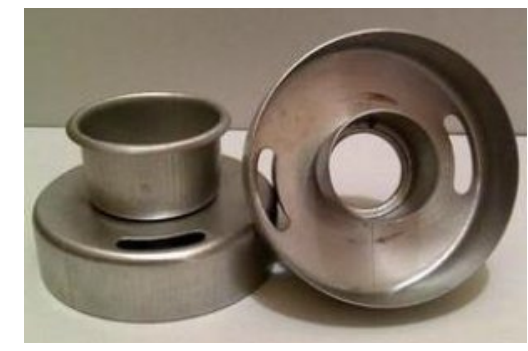

Gambar 4. Mangkok cetakan adonan donat dari Aluminium [4]
Dengan semakin pesatnya perkembangan teknologi yang dilakukan oleh perusahaan yang besar telah dibuat mesin pembuat donat secara otomatis sebagaimana Gambar 5 [5]. Volume tuang adonan donat dari mesin pembuat donat secara otomatis dapat diprogram, sehingga ukuran akhir donat setelah memuai karena digoreng diperoleh. Pada mesin pencetak donat otomatis, adonan setelah dicetak berbentuk cincin langsung masuk minyak penggorengan.

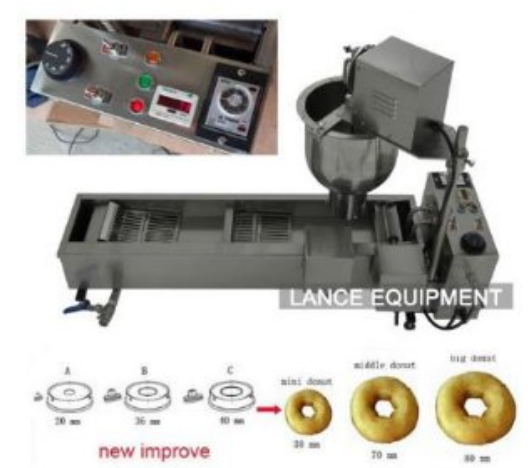

Gambar 5. Mesin pembuat donat secara otomatis [5]

Untuk bahan adonan yang cukup kenyal dimungkinkan digunakan alas-mangkok bahan plastik untuk menekan sekaligus memotongnya, sehingga menjadi suatu bentuk cincin berpenampang mendekati silindris yang pada bagian atasnya berpenampang setengah lingkaran dan pada bagian bawahnya mendekati segiempat sebagaimana Gambar 6 [6].

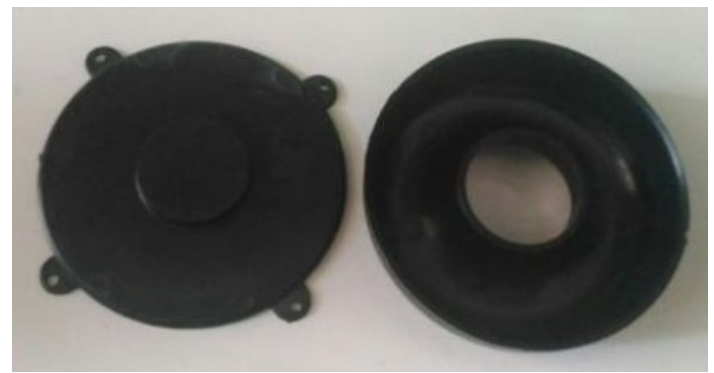

Gambar 6. Alas-Mangkok plastik pencetak adonan donat [6]

\section{Metode Penelitian}

Desain dan pembuatan cetakan pembuat cetakan plastik untuk adonan donat sebagaimana diagram alir pada Gambar 7 [7]. 


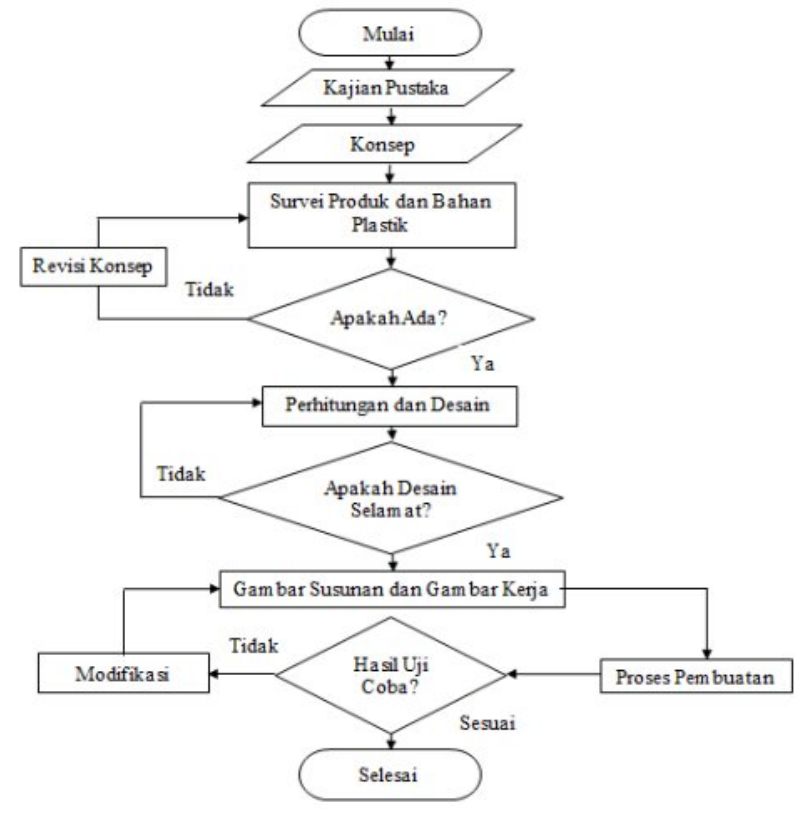

Gambar 7. Diagram alir desain dan pembuatan cetakan pembuat cetakan plastik untuk donat [7]

\section{A. Desain komponen}

Desain dan pembuatan cetakan plastik sistem injeksi untuk adonan donat meliputi: survey dimensi donat di pasaran, penentuan pemuaian adonan setelah digoreng untuk penentuan penyusutan/shrinkage pada dimensi cetakan, desain cetakan pada bagian atas dan bawah, desain sistem pendinginan, desain sistem untuk pendepakan produk cetakan, pembuatan gambar kerja, pemesinan komponen-komponen, perakitan, uji coba, dan perhitungan biaya produksi. Survey dimensi donat yang ada di pasaran adalah penting diperoleh untuk menentukan dimensi donat yang akan diproduksi, karena pemuaian bahan adonan setelah digoreng menentukan penyusutan dimensi cetakan yang akan dibuat cetakan plastiknya, termasuk memperkirakan harga jualnya setelah memperhitungkan laba yang diinginkan.

Gate adalah lubang masuknya cairan plastik ke dalam rongga cetakan. Desain produk dipengaruhi oleh: bentuk gate, penyusutan produk, gaya cekam cetakan, dan tekanan injeksi. Gate yang dipilih adalah sprue gate yang berbentuk kerucut terpancung. Dimensi gate dihitung dengan Rumus (1) [8]:

$$
\mathrm{A}_{\mathrm{g}}=\mathrm{G} / \rho . v \cdot \mathrm{t} \text { dengan } \mathrm{v}=\mathrm{C}_{\mathrm{a}} / \mathrm{A}_{\text {noz }}
$$

dengan: $\mathrm{A}_{\mathrm{g}}$ : penampang gate $\left(\mathrm{cm}^{2}\right)$, G: berat produk $(\mathrm{g})$, $\rho$ : massa jenis plastik $\left(\mathrm{g} / \mathrm{cm}^{3}\right)$, v: kecepatan alir bahan $(\mathrm{cm} / \mathrm{s})$, t: waktu pengisian cavity (s), $\mathrm{C}_{\mathrm{a}}$ : kapasitas alir mesin $\left(\mathrm{cm}^{3} / \mathrm{s}\right)$, dan $\mathrm{A}_{\text {noz: }}$ : penampang nozzle $\left(\mathrm{cm}^{2}\right)$.

Volume kerucut terpancung dihitung dengan Rumus (2) $[8]$ :

$$
\mathrm{V}_{\mathrm{s}}=(\pi \cdot \mathrm{t} / 3)\left(\mathrm{R}^{2}+\mathrm{r}^{2}+\mathrm{R} \cdot \mathrm{r}\right)
$$

dengan: $\mathrm{V}_{\mathrm{s}}$ : volume sprue gate $\left(\mathrm{mm}^{3}\right)$, t: tinggi lubang sprue gate $(\mathrm{mm})$, R: jari-jari lubang besar $(\mathrm{mm})$, dan $\mathrm{r}$ : jari-jari lubang kecil (mm).

Saluran penghubung (runner) antara aliran plastik dengan sprue pada rongga produk melalui gate didesain dengan bentuk dan dimensi sependek mungkin yang dapat mempermudah pembuatan, meminimalisasi kehilangan panas, mengurangi berat/volume runner yang terbuang dan menghindari penurunan tekanan, yang dihitung dengan Rumus (3) [8]:

$$
\mathrm{D}=\mathrm{S}_{\max }+1,5
$$

dengan: $\mathrm{D}$ : diameter runner $(\mathrm{mm})$, dan $\mathrm{S}_{\max }$ : ketebalan maksimal dinding produk $(\mathrm{mm})$.

Temperatur injeksi adalah temperatur leleh plastik saat diinjeksikan ke dalam cetakan melalui nozzle, untuk plastik PP, temperatur lelehnya $200-300^{\circ} \mathrm{C}$, dan temperatur dinding cavity-nya $20-100^{\circ} \mathrm{C}[8]$.

Tekanan injeksi (injection pressure, $p_{i n j}$ ) adalah besarnya tekanan yang diperlukan untuk injeksi lelehan plastik ke dalam rongga cetakan yang dihitung dengan Rumus (4) [8].

$$
\mathrm{p}_{\text {inj }}=\left(\mathrm{F}_{\mathrm{c} \text { mesin }}-\left(0,1 \mathrm{~F}_{\mathrm{c} \text { mesin }}\right)\right) / \mathrm{A}_{\text {proy }}
$$

Gaya cekam (clamping force, $\mathrm{F}_{\text {cekam mesin }}$ ) adalah gaya yang dibutuhkan untuk menahan kedua bagian cetakan agar tidak terbuka pada saat injeksi yang dihitung dengan Rumus (5) [8].

$$
\mathrm{F}_{\mathrm{c}}=\mathrm{p}_{\text {inj }} \cdot \mathrm{A}_{\text {proy }}
$$

dengan: $A_{\text {proy: }}$ luas proyeksi isian (total produk + runner + gate $)\left(\mathrm{cm}^{2}\right)$.

Kecepatan injeksi adalah kecepatan aliran lelehan plastik ke dalam rongga cetakan yang besarnya dipengaruhi oleh putaran ulir transporter dan dibatasi oleh kapasitas alir mesin serta diameter nozzle mesin yang dihitung dengan Rumus (6) [8]. 


$$
\mathrm{v}=\mathrm{Ca} / \mathrm{A}
$$

dengan: v: kecepatan alir bahan (cm/detik), Ca: kapasitas alir mesin $\left(\mathrm{cm}^{3} / \mathrm{s}\right)$, dan A: penampang nozzle $\left(\mathrm{cm}^{2}\right)$.

Waktu pengisian adalah waktu yang diperlukan untuk mengisi rongga cetakan hingga terisi penuh. Lamanya waktu pengisian berpengaruh pada cycle time pencetakan yang dihitung dengan Rumus (7) [8].

$$
\mathrm{t}=\mathrm{V} / \mathrm{Ca}
$$

dengan t: waktu injeksi (s), dan $\mathrm{V}$ : volume pengisian (produk + runner + sprue + gate $)\left(\mathrm{cm}^{3}\right)$.

Panas yang dibawa oleh lelehan plastik dilepaskan pada dinding cetakan selama pendinginan untuk menjaga kestabilan temperatur agar konstan selama pencetakan berulang-ulang yang jumlah kalor yang dilepaskan dinding cetakannya dihitung menggunakan pendekatan Menges-Mohren dengan Rumus (8) [8].

$$
\mathrm{Q}_{\mathrm{c}}=\mathrm{m}_{\mathrm{p}} \cdot \Delta \mathrm{h}_{\mathrm{a}}
$$

dengan: $\mathrm{Q}_{\mathrm{c}}$ : jumlah kalor yang dilepaskan plastik $(\mathrm{kJ} / \mathrm{h})$, $\mathrm{m}_{\mathrm{p}}$ : jumlah massa plastik yang dialirkan $(\mathrm{g})$, dan $\Delta \mathrm{h}_{\mathrm{a}}$ : selisih harga enthalpy mould (kkal).

Pendinginan cetakan terjadi karena ada perbedaan antara temperatur pada cetakan dan lingkungan luar cetakan, sehingga terjadi perpindahan panas. Panas yang hilang karena pengaruh lingkungan dihitung dengan Rumus (9) [8].

$$
\mathrm{Q}_{\mathrm{c}}=\mathrm{a}_{1} \cdot \mathrm{A}
$$

dengan: $\mathrm{Q}_{\mathrm{c}}$ : panas yang hilang $(\mathrm{J}), \mathrm{a}_{1}$ : specific heat loss $\left(\mathrm{J} / \mathrm{m}^{2}\right)$, dan A: luas permukaan produk $\left(\mathrm{m}^{2}\right)$.

Panjang saluran pendingin yang diperlukan untuk menyerap panas yang terjadi dihitung dengan Rumus (10) [8].

$$
\mathrm{L}=\left(\mathrm{Q}_{\mathrm{c}} .1\right) /(\alpha . \Delta \mathrm{T} . \Sigma \mathrm{A})
$$

dengan: L: panjang saluran pendingin $(\mathrm{cm}), \mathrm{Q}_{\mathrm{c}}$ : jumlah panas yang hilang (cal/s), l: jarak pendinginan terhadap permukaan cavity $(\mathrm{cm}), \alpha$ : koefisien perpindahan panas air terhadap baja 0,04-0,07 (cal/ $\left.\mathrm{cm}^{2} \mathrm{~s}^{\circ} \mathrm{C}\right), \Delta \mathrm{T}$ : temperatur dinding mould - temperatur air outlet $\left({ }^{\circ} \mathrm{C}\right)$, dan $\Sigma \mathrm{A}$ : jumlah luas permukaan cetakan $\left(\mathrm{cm}^{2}\right)$.

Waktu pendinginan adalah waktu yang diperlukan untuk mendinginkan cairan plastik hingga membentuk produk yang dihitung dengan Rumus (11) [8].

$$
\mathrm{t}_{\mathrm{ku}}=\frac{\mathrm{s}^{2} .4}{\alpha_{e f f .} \pi^{4}} \ln \left(\frac{8 \mathrm{~T}_{\mathrm{m}}-\mathrm{T}_{\mathrm{w}}}{\pi^{2} \mathrm{~T}_{\theta}-\mathrm{T}_{\mathrm{w}}}\right)
$$

dengan: $t_{k u}$ : durasi pendinginan (s), s: tebal Produk (mm), $\propto_{\text {eff }}$ : effective thermal diffusivity plastik $\left(\mathrm{mm}^{2} / \mathrm{s} / 10^{-4}\right), \mathrm{T}_{\mathrm{m}}$ : temperatur leleh $\left({ }^{\circ} \mathrm{C}\right), \mathrm{T}_{\mathrm{w}}$ : temperatur dinding $\left({ }^{\circ} \mathrm{C}\right), \mathrm{T}_{\mathrm{e}}$ : temperatur sentak $\left({ }^{\circ} \mathrm{C}\right)$.

Penyusutan adalah pengecilan dimensi produk aktual terhadap dimensi rongga cetak yang dihitung dengan Rumus (12) [8].

$$
\mathrm{S}_{\mathrm{v}}=1-\left(\mathrm{V} / \mathrm{V}_{\mathrm{c}}\right)
$$

dengan: $\mathrm{S}_{\mathrm{v}}$ : volume penyusutan, $\mathrm{V}_{\mathrm{c}}$ : volume cavity pada temperatur ruang, dan $\mathrm{V}$ : volume produk pada temperatur ruang.

Dalam cetakan terdapat udara yang terjebak dalam cetakan karena terdapat rongga antara plate cavity dan plate core. Saat pengisian plastik berlangsung, udara tersebut harus dihilangkan. Pada saat injeksi berkecepatan tinggi, venting yang tidak memadai pada cetakan dalam menghasilkan kompresi udara yang tinggi akibat terjebaknya udara dalam rongga cetakan. Pengaruh venting tersebut dapat mengkibatkan proses pengisian lelehan plastik dalam rongga cetakan menjadi pelan dan dapat mengakibatkan temperatur udara dalam ronggga cetakan menjadi tinggi, yang berakibat plastik terbakar dan produk menjadi rusak. Umumnya venting dibuat antara pertemuan plate core dan pate cavity dengan nilai antara $0,0025 \mathrm{~mm}$ dan $0,035 \mathrm{~mm}$.

Secara mekanik kekuatan cetakan harus dibuat tahan terhadap tekanan injeksi, gaya pencekaman dan temperatur injeksi.

Desain cetakan pada bagian atas (upper cavity plate) sebagaimana Gambar 8 [7] dan cetakan pada bagian bawah (lower cavity plate) sebagaimana Gambar 9 [7] merupakan setangkup cetakan yang dibuat dari baja (ST 60) [8] dengan dimensi yang akurat untuk memperoleh hasil cetakan plastik yang presisi. 


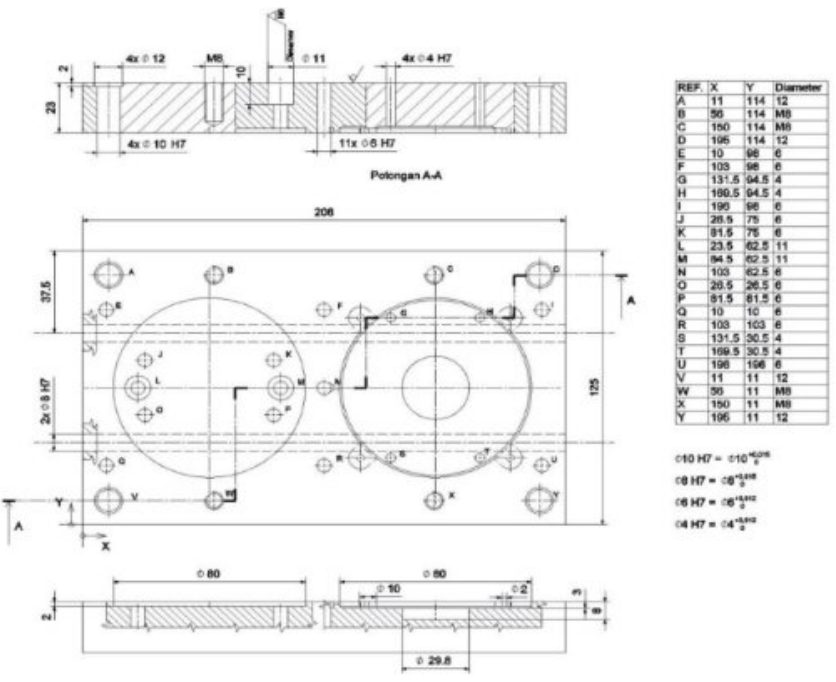

Gambar 8. Cetakan bagian atas (upper cavity plate) [7]
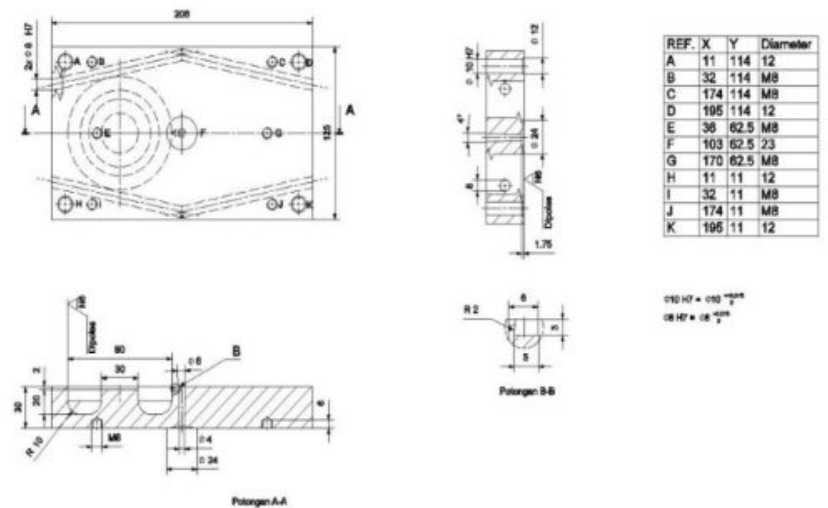

Gambar 9. Cetakan bagian bawah (lower cavity plate) [7]

Untuk membuat bentuk lubang di dalam cetakan harus dibuat inti (insert core) yang dibuat dari baja (ST 60) [8] sebagaimana Gambar 10 [7].

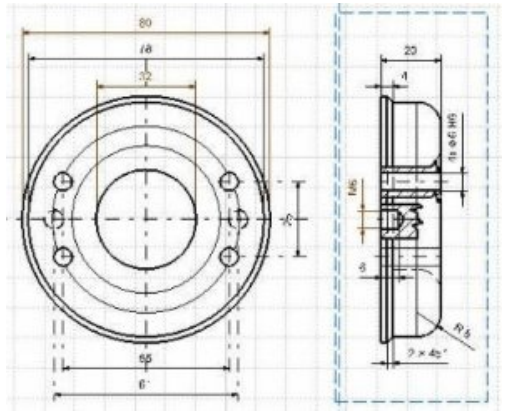

Gambar 10. Inti (insert core) pembuat bentuk rongga di dalam cetakan [7]

Kedua cetakan atas dan cetakan bawah dihubungkan dengan pena pengarah (guide pin) sebagaimana Gambar 10 [7] dan batang penaik (rise bar) sebagaimana Gambar
11 [7] agar tangkupannya selalu tepat saat dibuka maupun ditutup.

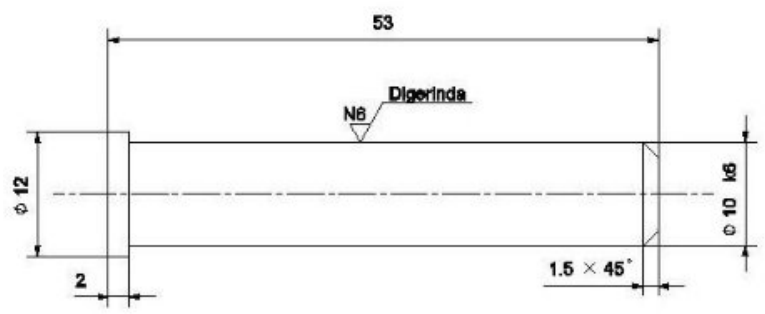

Gambar 10. Pena pengarah (guide pin) [7]
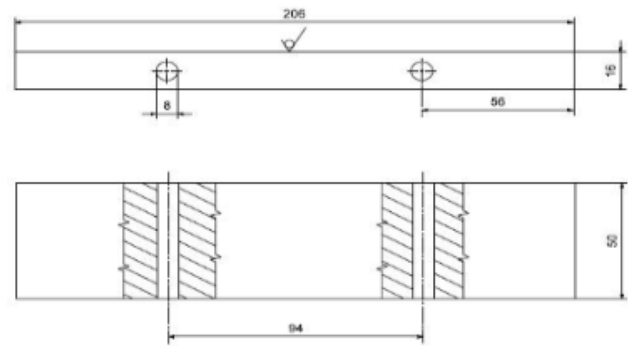

Gambar 11. Batang penaik (rise bar) untuk penangkupan cetakan atas dan cetakan bawah [7]

Penyangga batang penaik sebagaimana Gambar 12 [7].
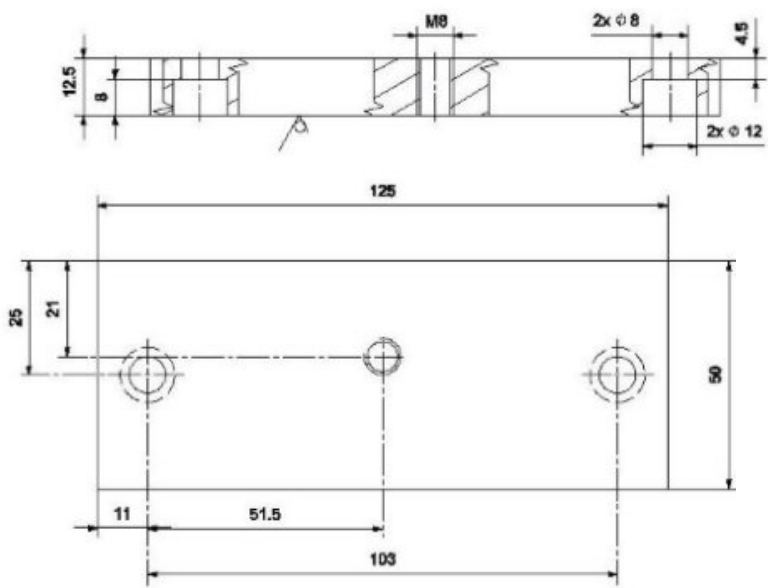

Gambar 12. Penyangga batang penaik [7]

Untuk mengeluarkan produk hasil cetakan dari dalam cetakan digunakan pelat pemegang pendepak (ejector holder plate) sebagaimana Gambar 13 [7] yang berfungsi untuk tempat pemasangan pena pendepak (Pin Ejector) dan pena penyelamat (Safety Pin). Pena penyelamat berfungsi untuk mengembalikan posisi cetakan seperti semula setelah melakukan injeksi dan pengeluaran 
produk dari cetakan, agar cetakan siap digunakan untuk proses injeksi selanjutnya.
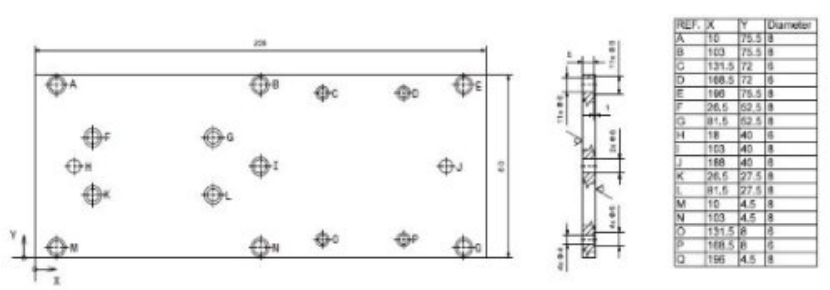

Gambar 13. Pelat pemegang pendepak (Ejector Holder Plate) [7]

Pelat bawah (bottom plate) sebagaimana Gambar 14 [7] berfungsi untuk menempatkan pendepak-pendepak di bawah cetakan atas dan cetakan bawah, sehingga antar cetakan atas dan cetakan bawah dapat bergerak menjauh dan mendekat bila pendepak difungsikan.
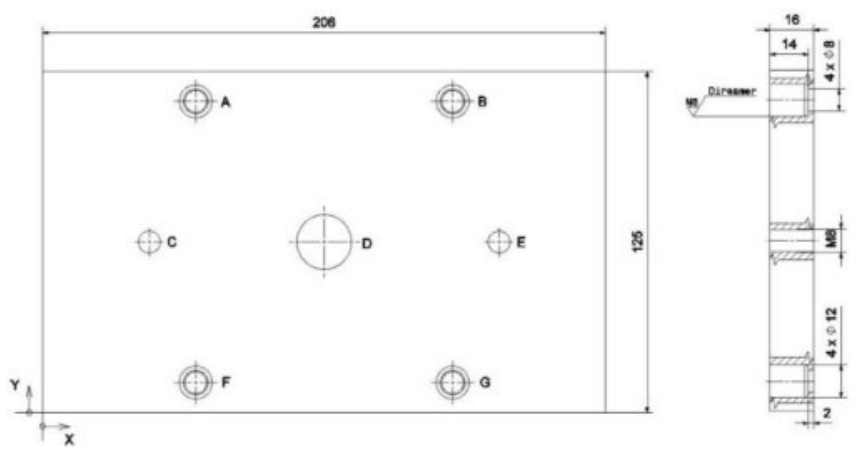

Gambar 14. Pelat bawah (bottom plate) [7]

Pena-pena pendepak A, B, dan C sebagaimana Gambar 15 [7].
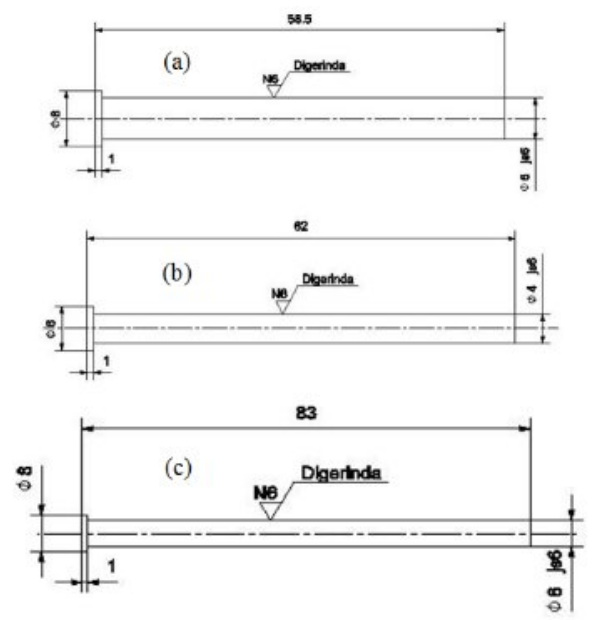

Gambar 15. Pena pendepak A, pena pendepak B, dan pena pendepak C [7]
Desain sistem pendinginan digunakan air sebagai media pendinginnya dengan lubang pendingin berdiameter $8 \mathrm{~mm}$ dengan saluran air masuk-keluar (nipple) sebagaimana Gambar 16 [7].

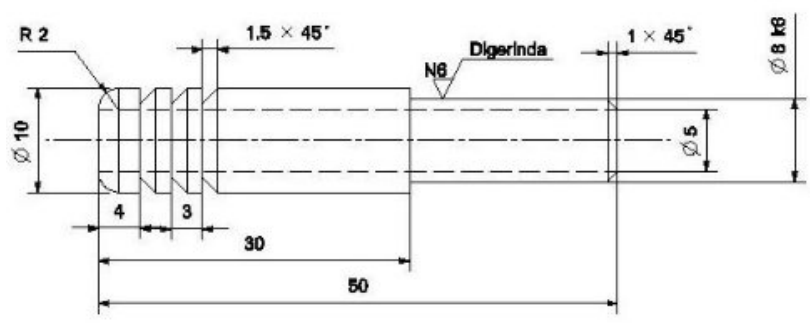

Gambar 16. Saluran air masuk-keluar (nipple) [7]

Spesifikasi Mangkok/cetakan adonan donat adalah plastik $P P$, temperatur kerja: $160-250^{\circ} \mathrm{C}$, temperatur keluar dari cetakan: $60-100^{\circ} \mathrm{C}$, temperatur dinding cavity: $20-100^{\circ} \mathrm{C}$, massa jenis: $0.91 \mathrm{~g} / \mathrm{cm}^{3}$, volume: $17,52 \mathrm{~cm}^{3}$, berat produk: $15,9 \mathrm{~g}$, luas: $180 \mathrm{~cm}^{2}$, dan tebal: $2 \mathrm{~mm}$.

Spesifikasi Alas cetakan adonan donat adalah plastik $P P$, temperatur kerja: $160-250^{\circ} \mathrm{C}$, temperatur keluar dari cetakan: $60-100^{\circ} \mathrm{C}$, temperatur dinding cavity: $20-100^{\circ} \mathrm{C}$, massa jenis: $0.91 \mathrm{~g} / \mathrm{cm}^{3}$, volume: $18,7 \mathrm{~cm}^{3}$, berat produk: $17,0 \mathrm{~g}$, luas: $120 \mathrm{~cm}^{2}$, dan tebal: $3 \mathrm{~mm}$.

Spesifikasi mesin injeksi: Po Yuen Machine, Tipe: PYI-45PC, Tekanan injeksi: $1785 \mathrm{kgf} / \mathrm{cm}^{2}$, Injection rate: $89 \mathrm{~cm}^{3} / \mathrm{s}$, Maximum injection capacity: $51 \mathrm{~cm}^{3}$, Kapasitas plasticizing: $26 \mathrm{~kg} / \mathrm{jam}$, Clamping force: 50 $\mathrm{kN}$, dan Kapasitas alir mesin: $245 \mathrm{~cm}^{3} / \mathrm{s}$.

Pendinginan menggunakan media pendinginan air dengan temperatur air masuk: $25^{\circ} \mathrm{C}$, temperatur air keluar: $30^{\circ} \mathrm{C}, \phi$ saluran pendingin: $8 \mathrm{~mm}$, dan viskositas kinematis air: $1 \mathrm{~cm}^{2} / \mathrm{s}$.

Siklus pencetakan cetakan adonan donat dengan: waktu buka: $8 \mathrm{~s}$, waktu tutup: $9 \mathrm{~s}$, waktu injeksi: $35 \mathrm{~s}$, cooling time: $50 \mathrm{~s}$, holding time: $14 \mathrm{~s}$, waktu pengeluaran produk: $4 \mathrm{~s}$, dan waktu total: $120 \mathrm{~s}$.

\section{B. Pemesinan komponen}

Pemesinan komponen cetakan dilakukan dengan menggunakan beberapa mesin diantaranya: Mesin gergaji, Mesin bor, Mesin Frais, Mesin Bubut, Mesin gerinda permukaan, dan alat poles. 


\section{Perakitan komponen}

Perakitan dilakukan untuk menyatukan semua komponen menjadi satu kesatuan sebagai sepasang cetakan sistem injeksi pembuat cetakan adonan donat dari bahan plastik $P P$ sebagaimana Gambar 17 [7]

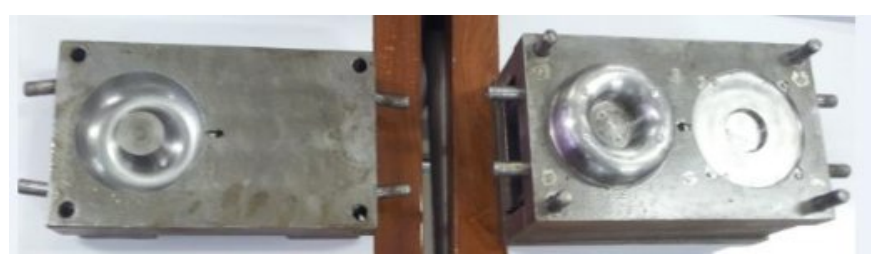

Gambar 17. Hasil perakitan semua komponen menjadi satu kesatuan sepasang cetakan sistem injeksi pembuat cetakan adonan donat dari bahan plastik [7]

\section{Uji coba cetakan sistem injeksi}

Uji coba cetakan sistem injeksi pembuat cetakan adonan donat dari bahan plastik menggunakan mesin cetak injeksi dengan hasil produk cetakan donat sebagaimana Gambar 18 [7].
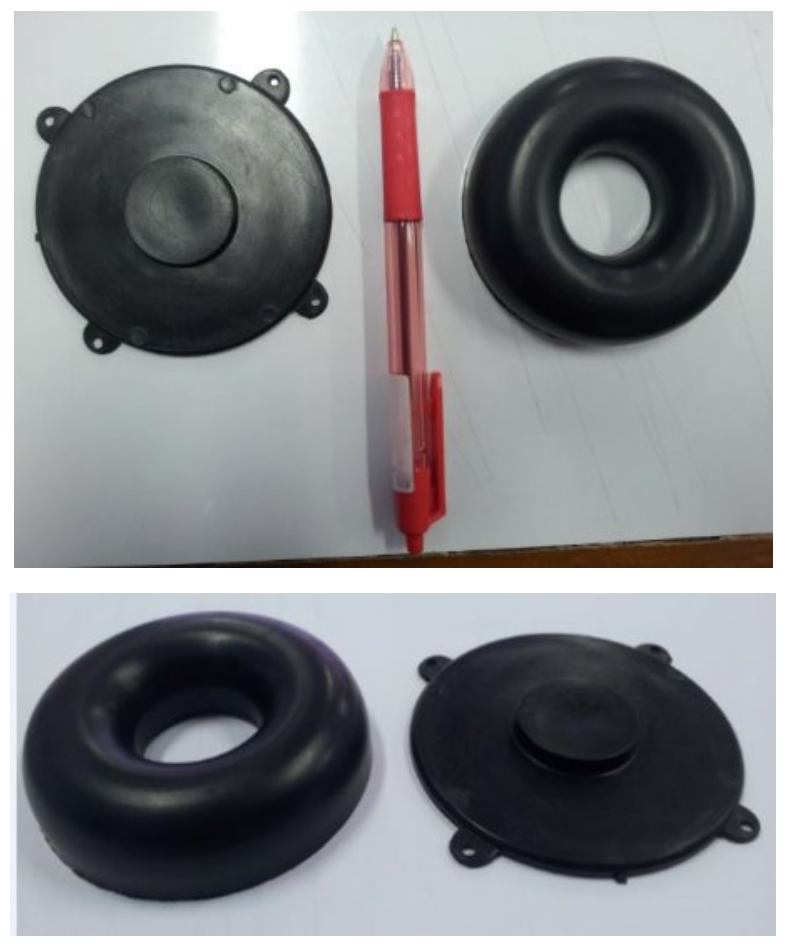

Gambar 18. Hasil uji coba cetakan sistem injeksi pembuat cetakan donat dari bahan plastik [7].

Desain dan pembuatan dilaksanakan di Laboratorium dan Bengkel, Jurusan Teknik Mesin, Politeknik Negeri Malang, Jl. Soekarno-Hatta 9 Malang, pada bulan MeiAgustus 2016.

\section{E. Estimasi biaya produksi}

Daftar harga bahan baja yang terdapat di pasaran sebagaimana Tabel 1.

Tabel 1. Daftar harga bahan di pasaran

\begin{tabular}{|c|l|c|r|}
\hline No. & Nama Bahan & $\rho\left(\mathrm{kg} / \mathrm{mm}^{3}\right)$ & Harga $(\mathrm{Rp} / \mathrm{kg})$ \\
\hline 1 & St 42 & $7,8 \times 10^{-6}$ & $14.000,-$ \\
\hline 2 & St 60 & $7,8 \times 10^{-6}$ & $25.000,-$ \\
\hline
\end{tabular}

Contoh perhitungan bahan lower cavity plate dengan bahan St 60. Ukuran lower cavity plate $=210 \mathrm{~mm} \times$ $128 \mathrm{~mm} \times 35 \mathrm{~mm}$ memunyai massa jenis $(\rho)=7,8 \times 10-6$, maka $\mathrm{W}=\rho \times \mathrm{V}=7,85 \times 10^{-6} \mathrm{~kg} / \mathrm{mm}^{3} \times(\mathrm{p} \times 1 \times \mathrm{t})=$ $7,85 \times 10^{-6} \mathrm{~kg} / \mathrm{mm}^{3} \times(210 \mathrm{~mm} \times 128 \mathrm{~mm} \times 35 \mathrm{~mm})=$ $7,38 \mathrm{~kg}$. Jadi harga bahan lower cavity plate $=7,38 \mathrm{~kg} \mathrm{x}$ Rp 25.000,-/kg = Rp 184.500,-.

Hasil perhitungan komponen-komponen cetakan sebagaimana Tabel 2 dan Tabel 3.

Tabel 2. Harga bahan baku bukan order

\begin{tabular}{|c|l|c|c|c|c|c|}
\hline No. & Nama Bagian & Bahan & Ukuran $(\mathrm{mm})$ & $\begin{array}{c}\text { Jum- } \\
\text { lah }\end{array}$ & $\begin{array}{c}\text { Berat } \\
(\mathrm{kg})\end{array}$ & $\begin{array}{c}\text { Harga } \\
(\mathrm{Rp})\end{array}$ \\
\hline 1 & $\begin{array}{l}\text { Lower Cavity } \\
\text { Plate }\end{array}$ & St 60 & $210 \times 128 \times 35$ & 1 & 10 & 184.500 \\
\hline 2 & $\begin{array}{l}\text { Upper Cavity } \\
\text { plat }\end{array}$ & St 60 & $210 \times 128 \times 25$ & 1 & 9 & 225.000 \\
\hline 3 & Buttom plate & St 42 & $210 \times 128 \times 20$ & 1 & 4 & 56.000 \\
\hline 4 & Pin ejector $A$ & St 42 & $\varnothing 8 \times 60$ & 4 & 1 & 14.000 \\
\hline 5 & $\begin{array}{l}\text { Ejector back } \\
\text { plate }\end{array}$ & St 42 & $210 \times 85 \times 10$ & 1 & 2,3 & 35.000 \\
\hline 6 & Nipple & St 42 & $\varnothing 15 \times 55$ & 8 & 0.15 & 8.400 \\
\hline 7 & Rise bar B & St42 & $128 \times 55 \times 14$ & 2 & 1,8 & 26.000 \\
\hline 8 & Rise Bar $A$ & St 42 & $210 \times 55 \times 20$ & 2 & 4 & 56.000 \\
\hline 9 & $\begin{array}{l}\text { Ejector holder } \\
\text { plate }\end{array}$ & St 42 & $210 \times 83 \times 10$ & 1 & 2 & 28.000 \\
\hline 10 & Pin safety & St 42 & $\varnothing 8 \times 70$ & 6 & 1 & 14.000 \\
\hline 11 & Guide pin & St 42 & $\varnothing 12 \times 55$ & 4 & 1 & 14.000 \\
\hline 12 & Insert core & St 60 & $\varnothing 85 \times 20$ & 1 & 1 & 25.000 \\
\hline 13 & Pin ejector B & St 42 & $\varnothing 8 \times 90$ & 4 & 1 & 14.000 \\
\hline 14 & Pin ejektor $C$ & St 42 & $\varnothing 6 \times 70$ & 4 & 1 & 14.000 \\
\hline & Harga total & & & & & 713.900 \\
\hline
\end{tabular}

Tabel 3. Harga bahan baku order

\begin{tabular}{|c|l|l|c|c|c|}
\hline No. & Nama Bagian & $\begin{array}{c}\text { Ukuran } \\
(\mathrm{mm})\end{array}$ & $\begin{array}{c}\text { Harga } \\
\text { Satuan } \\
(\mathrm{Rp})\end{array}$ & Jumlah & $\begin{array}{c}\text { Harga } \\
(\mathrm{Rp})\end{array}$ \\
\hline 1 & Baut Inbus & M8 x 61 & 1.000 & 3 & 3.000 \\
\hline 2 & Baut Inbus & M6 x 11 & 2.000 & 2 & 4.000 \\
\hline & & Harga total & & & 7.000 \\
\hline
\end{tabular}

Jadi harga total bahan baku= harga bahan baku bukan order + order $=\mathrm{Rp} \mathrm{713.900,-}+\mathrm{Rp} \mathrm{7.000,-}=\mathrm{Rp}$ 720.900,- 


\section{Hasil dan Pembahasan}

Hasil-hasil desain, pembuatan, dan ujicoba cetakan pembuat cetakan plastik untuk adonan donat meliputi:

1) Diameter adonan donat sebelum digoreng adalah 76 $\mathrm{mm}$ dan setelah digoreng adalah $82 \mathrm{~mm}$, berarti pemuaiannya adalah $7 \%$. Setelah melewati proses fermentasi, adonan donat dapat dikempiskan dari yang telah mengembang sebelumnya [9].

2) Harga bahan baku baja total adalah $\mathrm{Rp} 720.900,-$,

3) Waktu pengerjaan total dalam pembuatan cetakan plastik untuk adonan donat adalah 988.12 menit, waktu pengerjaan total meliputi waktu pengerjaan secara manual maupun pemesinan,

4) Biaya pembuatan cetakan plastik untuk adonan donat adalah Rp 4.300.000,- satu set,

5) Harga jual produk cetakan plastik untuk adonan donat $\mathrm{Rp} 8.000,-/$ tangkup,

6) Jumlah produk untuk mencapai BEP (Break Event Point) adalah 5650 tangkupan atau ditempuh dalam jangka waktu produksi menerus selama 12 hari (12 jam kerja/hari) efektif,

7) Spesifikasi cetakan plastik sistem injeksi dengan dimensi $206 \mathrm{~mm} \times 125 \mathrm{~mm} \times 131,5 \mathrm{~mm}$,

Spesifikasi produk cetakan:

a. Volume cetakan adonan donat $\phi 80 \times 20 \mathrm{~mm}$ adalah $17,52 \mathrm{~cm}^{3}$, dan volume Aalas adonan donat $\phi 80 \times 8$ mm adalah $18,71 \mathrm{~cm}^{3}$,

b. Berat produk Mangkok/cetakan adonan donat $\phi 80 \mathrm{x}$ $20 \mathrm{~mm}$ adalah 15,943 $\mathrm{g}$, dan berat produk Alas adonan donat $\phi 80 \times 8 \mathrm{~mm}$ adalah $17,026 \mathrm{~g}$, dan

c. Jumlah cavity 2 buah.

\section{Simpulan}

Simpulan hasil desain, pembuatan, dan ujicoba meliputi:

1. Pemuaian adonan donat sebelum dan sesudah digoreng adalah $7 \%$,

2. Biaya pembuatan cetakan plastik untuk adonan donat adalah $\mathrm{Rp}$ 4.300.000,- untuk satu set dengan waktu pengerjaan total 988 menit,
3. Harga jual produk cetakan plastik untuk adonan donat Rp 8.000,-/tangkup,

4. Jumlah produk untuk mencapai BEP adalah 5650 tangkup atau ditempuh dalam jangka waktu produksi menerus selama 12 hari (12 jam kerja/hari) efektif,

5. Spesifikasi Mangkok/cetakan plastik sistem injeksi berdimensi $206 \mathrm{~mm} \times 125 \mathrm{~mm} \times 131,5 \mathrm{~mm}$, dan spesifikasi produk cetakan adonan $\phi 80 \mathrm{x}$ tinggi 20 $\mathrm{mm}$, Alas cetakan adonan $\phi 80 \mathrm{x}$ tinggi $8 \mathrm{~mm}$ dengan berat $33 \mathrm{~g} /$ tangkup.

Saran atas simpulan dari desain, pembuatan, dan ujicoba meliputi:

1. Perbedaan resep adonan mengakibatkan perbedaan pemuaian, sehingga dengan perbedaan adonan, dimensi hasil penggorengan ikut berbeda,

2. Aneka cetakan kue dapat dikembangkan dengan desain dan pembuatan dengan cara yang serupa.

\section{Ucapan Terima Kasih}

Terima kasih disampaikan kepada Jurusan Teknik Mesin, Politeknik Negeri Malang atas dukungan fasilitas Bengkel Pemesinan dalam pembuatan cetakan.

\section{Daftar Pustaka}

[1] Anonim, 2016a, "Cetakan Donat Kecil Stainless Steel", https://www.google.co.id/, diakses tanggal 8 Oktober 2016.

[2] Anonim, 2016b, "Irus Cetakan Donat Cair", diakses tanggal 8 Oktober 2016.

[3] Anonim, 2016c, "Wajan Pembuat Donat", https://www.google.co.id/, diakses tanggal 8 Oktober 2016.

[4] Anonim, 2016d, "Cetakan Donat dari Aluminium", https://www.google.co.id/, diakses tanggal 8 Oktober 2016.

[5] Anonim, 2016e, "Mesin Pembuat Donat", https://www.google.co.id/, diakses tanggal 8 Oktober 2016.

[6] Sayekti, Saifudin Kalih, 2016. "Pembuatan Cetak Plastik Sistem Injeksi Cetakan Adonan Donat Kapasitas 30 Produk/Jam", Jurusan Teknik Mesin, Politeknik Negeri Malang, Malang.

[7] Murti, Tandya Nanda Haswari, 2016. "Desain Cetak Plastik Sistem Injeksi Cetakan Adonan Donat Kapasitas 30 Produk/Jam”, Jurusan Teknik Mesin, Politeknik Negeri Malang, Malang.

[8] Budiarto, 2002. "Perancangan Peralatan Pencetak", Politeknik Manufaktur, Bandung.

[9] Hadi, Syamsul, 2016. "Teknologi Bahan", Andi Offset, Yogyakarta.

[10] Anonim 2016f, "Tips dan Technique dalam Pembuatan Donat", file:///C:/Users/syamsul/Downloads/Teknik\%20dalam\%20Pemb uatan\%20Donat.pdf diakses tanggal 9 Oktober 2016. 